\title{
Oocyte quality in small antral follicles in the presence or absence of a large dominant follicle in cattle
}

\author{
L. C. Smith ${ }^{1}$, M. Olivera-Angel ${ }^{1 *}$, N. P. Groome ${ }^{2}$, B. Bhatia $^{1}$ and \\ C. A. Price ${ }^{1}$ \\ ${ }^{1}$ Centre de recherche en reproduction animale, Faculty of Veterinary Medicine, University of Montreal, \\ St-Hyacinthe, Quebec, Canada; and ${ }^{2}$ School of Biological and Molecular Sciences, Oxford Brookes \\ University, Oxford, UK
}

\begin{abstract}
The aim of these experiments was to determine whether the presence of a dominant follicle affects the developmental competence of oocytes from small antral follicles of cattle. In Expt 1 , oocytes or follicular fluid samples were collected from follicles $2-7 \mathrm{~mm}$ in diameter before (day 3 of the oestrous cycle; $n=4$ ) or after (days 6 and 7 of the oestrous cycle; $n=6$ ) emergence of the first wave dominant follicle (verified by rectal ultrasonography). Five to ten follicles were aspirated for the determination of individual follicular fluid concentrations of oestradiol, progesterone, testosterone and dimeric inhibin; oocytes from the remaining follicles from each cow were pooled and developmental capacity assessed by in vitro fertilization and maturation. In Expt 2, ovaries containing a young corpus luteum and with or without a large oestrogen-active follicle were collected from the abattoir. Follicular aspirates from small follicles in each pair of ovaries were pooled, and oocyte quality and steroid concentrations were determined. In Expt 1, small follicles obtained before emergence of the dominant follicle contained significantly more oestradiol than they did after emergence (19.5 \pm 1.5 versus $0.7 \pm 1.1 \mathrm{ng} \mathrm{ml}^{-1}$, respectively; $P<0.05$ ), but there were no significant differences in concentrations of progesterone, testosterone or dimeric inhibin. The percentage of blastocysts obtained from oocytes collected before (12.1 \pm 9.0 ) or after emergence (11.8 \pm 7.0 ) of the dominant follicle did not differ significantly $(P>0.05)$. In Expt 2 , follicular steroid concentrations did not differ in small follicles taken in the presence versus the absence of a large oestrogen-active follicle, and there were no differences in the developmental capacity of the oocytes. There were significant negative correlations between follicular oestradiol concentration and the percentage of blastocysts formed from two-cell $(r=-0.90 ; P<0.01)$ and eight-cell embryos $(r=-0.65 ; P<0.05)$. These data suggest that in cattle the developmental competence of oocytes from small antral follicles is not adversely affected by the presence of a dominant follicle.
\end{abstract}

\section{Introduction}

The production of embryos by in vitro maturation, fertilization and culture of oocytes aspirated directly from ovarian follicles is performed for therapeutic reasons in humans, for production purposes in domestic animals, and for experimental research in laboratory mammals. In cattle, ovaries obtained from the abattoir constitute an economical source of oocytes, although the quality of these oocytes is highly variable (review by Brackett and Zuelke, 1993). The use of defined morphological criteria in the selection of cumulus-oocyte complexes has led to limited improvement in the identification of the oocytes that will succeed in in vitro fertilization (IVF) (DeLoos et al., 1989). It is possible that the intrafollicular environment to which

*On sabbatical leave from the Universidad National de Colombia, Bogotá, Colombia.

Received 8 September 1995 oocytes are exposed is a major cause of the variability in developmental competence of the oocytes (Callesen et al., 1986).

Healthy large antral follicles in cattle are characterized by high intrafollicular oestradiol concentrations, whereas atretic follicles contain higher progesterone or androgen concentrations (Ireland and Roche, 1983; Grimes et al., 1987; Spicer et al., 1987) and higher concentrations of dimeric inhibin (Guilbault et al., 1993; Hopko Ireland et al., 1994). However, most oocytes used in IVF are aspirated from small antral follicles $(2-7 \mathrm{~mm})$, and although it is known that morphologically degenerated follicles contain lower oestradiol concentrations than do non-degenerated follicles (Kruip and Dieleman, 1982), less is known about the effect of stage of cycle on the health of small follicles. Small follicles obtained during the early luteal phase (days 1-8) contain less testosterone than do follicles obtained during the late luteal phase (days 9-17), 
although intrafollicular concentrations of oestradiol and progesterone do not differ (Kruip and Dieleman, 1985). However, Spicer and Zinn (1987) found that small and medium follicles contained higher oestradiol concentrations in the early (days 1-10) compared with the late (days 11-17) luteal phase. These studies imply that small follicles in the midluteal phase are more likely to be atretic than are those present in the early luteal phase.

The atresia of small follicles is thought to be related to the presence of the large dominant follicle. The development of a dominant follicle is closely associated with the regression of subordinate follicles, and new growth of small follicles occurs only once the large dominant follicle has ceased growing (Savio et al., 1988; Sirois and Fortune, 1988). Gonadotrophin treatment for superovulation recruits small follicles $(\leq 6 \mathrm{~mm})$, and evidence has been presented that the presence of a dominant follicle decreases ovulation rate and the number of transferable embryos (Guilbault et al., 1991; Bungartz and Niemann, 1994). The presence of a dominant follicle may therefore indicate a cohort of atretic small follicles, which may not be appropriate for commercial oocyte collection.

The aim of the present study was to test the hypothesis that the presence of a dominant follicle decreases the developmental capacity of oocytes from small follicles, and that this decrease is accompanied by increased hormonal signs of atresia.

\section{Materials and Methods}

\section{Experiment 1}

Animals. Ten crossbred Holstein Friesian heifers, 18 months old, were housed indoors at the Centre's farm in St-Hyacinthe, Quebec (latitude $45^{\circ} 30^{\prime} \mathrm{N}$ ), and were maintained under standard husbandry conditions. Oestrus detection was conducted daily to verify that the animals were displaying regular oestrous cycles before the start of the experiment, which took place in June.

Oestrous cycles were synchronized with two injections of prostaglandin $\mathrm{F}_{2 u}$ (500 mg Estrumate; Coopers Agropharm Inc., Ajax, Ontario) given 13 days apart. Follicle development was monitored with ultrasonography (Tokyo Keiki Co., Tokyo; $5 \mathrm{MHz}$ probe) twice a day, starting several days before the second prostaglandin injection. Heifers were then slaughtered during the first follicular wave, before (day 3 of the oestrous cycle; Group 1; $n=4$ ) or after (days 6 and 7 of the oestrous cycle; Group 2; $n=6$ ) a single follicle was distinguished by ultrasound that exceeded the diameter of other follicles (the dominant follicle). The pattern of follicle growth at this time has been well described (Savio et al., 1988; Sirois and Fortune, 1988; Guilbault et al., 1993).

Immediately after slaughter, the ovaries were removed and transported at $30-35^{\circ} \mathrm{C}$ to the laboratory. Five to ten small follicles (2-7 mm in diameter) were aspirated individually from both ovaries of each cow at random. The follicular fluids were centrifuged at $1000 \mathrm{~g}$ for $5 \mathrm{~min}$ to remove cell debris, and were then frozen at $-20^{\circ} \mathrm{C}$ until hormone assay. Follicular aspirates from the remaining small follicles (approximately 10-20 follicles) from each cow were pooled for the collection of oocytes.
Oocyte maturation and fertilization. The sediment from the follicular fluid pools was removed with a Pasteur pipette into a Petri dish and cumulus-oocyte complexes were collected and washed in Hepes-buffered M199 (Gibco BRL Canada, Burlington, Ontario) with $10 \%$ fetal calf serum (FCS) (Gibco). Complexes with a complete cumulus cover were placed into $50 \mu \mathrm{l}$ drops of bicarbonate-buffered M199 (Gibco) supplemented with $10 \% \mathrm{FCS}, 5 \mu \mathrm{g} \mathrm{LH} \mathrm{ml}^{-1}$ (APL, Ayerst, Montreal), $0.5 \mu \mathrm{g} \mathrm{FSH} \mathrm{ml}^{-1}$ (Folltropin-V: Vetrepharm, London, Ontario) and $1 \mu$ g oestradiol $\mathrm{ml}^{-1}$ (Sigma Chemical Co., St Louis, MO) and matured at $39^{\circ} \mathrm{C}$ and in $5 \% \mathrm{CO}_{2}$ in air for $24 \mathrm{~h}$. After maturation, oocytes were washed and fertilized in modified Tyrode's medium, following the protocol described by Parrish et al. (1986). In brief, oocytes were transferred to TALP medium containing $10 \mathrm{mg}$ heparin $\mathrm{ml}^{-1}$ and incubated with $10^{\circ}$ frozen-thawed spermatozoa $\mathrm{ml}^{-1}$. The spermatozoa used in both experiments were from the same bull.

Embryo culture and evaluation. After co-incubation of the spermatozoa and oocytes for $18 \mathrm{~h}$, presumptive zygotes were placed in culture in Ménézo's B2 medium (bioMérieux sa, Paris) supplemented with $10 \%$ oestrous cow serum in the presence of approximately 20 'clumps' of bovine oviductal epithelial cells (Xu et al., 1992). The culture medium was replenished every 2 days, and the stage of development was assessed by counting the number of cleavage and eight-cell embryos after 2 days, and the number of blastocysts after 7 days of culture. Embryos that had developed a blastocoel with an inner cell mass were classified as blastocysts. Blastocysts were fixed and stained to count nuclei using a technique described by Pursel et al. (1985). Briefly, blastocysts were placed on a glass slide, counterstained with trypan blue, stained with Hoechst 33342 , and embedded between the slide and coverslip in Permount (Sigma) and then examined by fluorescence microscopy.

\section{Experiment 2}

Pairs of ovaries were collected from a local abattoir during winter, and transported to the laboratory at $30-35^{\circ} \mathrm{C}$. Ovaries were selected that were judged to be in the early luteal phase of the cycle, as determined by the appearance of the corpus luteum (Ireland et al., 1980), and were subdivided into those with, and those without, a follicle greater than $8 \mathrm{~mm}$ in diameter. Follicular fluid from the large follicle was aspirated for steroid assay, and ovaries were included in the analysis only if the large follicle was judged to be dominant (oestradiol: progesterone ratio greater than 1; Price et al., 1995a). All small follicles from each pair of ovaries were aspirated; the fluid was pooled and complete cumulus-oocyte complexes were removed. The remaining fluid was frozen for hormone assay. Oocyte maturation and fertilization, and embryo culture were performed as described for Expt 1 above, except that approximately twice the number of bovine oviductal epithelial cells were added per culture (50 'clumps' per drop; Xu et al., 1992).

\section{Hormone assays}

Fluid samples obtained from individual small follicles (Expt I) or fluid pools (Expt 2) were diluted 1:100 in assay buffer, and Downloaded from Bioscientifica.com at 04/26/2023 01:08:27PM 
Table 1. Mean ( \pm SEM) numbers of oocytes recovered per heifer, and numbers (percentages in parentheses) of embryos that developed to cleavage and eight-cell stage by day 2 of culture, and to blastocyst stage by day 7 of culture, when obtained from small antral follicles recovered before ( $n=4$ heifers) and after ( $n=6$ heifers) the emergence of the first-wave dominant follicle

\begin{tabular}{lcrrr}
\hline & $\begin{array}{c}\text { Average } \\
\text { number } \\
\text { of oocytes }\end{array}$ & Cleaved & Number of embryos \\
\cline { 3 - 5 } & $19.0 \pm 3.3$ & $12.5 \pm 2.0^{\mathrm{a}}$ & $5.8 \pm 1.8$ & Blastocyst \\
\hline Before emergence & & $(68.7 \pm 5.0)$ & $(26.2 \pm 10.5)$ & $\begin{array}{c}2.5 \pm 1.0 \\
\text { After emergence }\end{array}$ \\
\cline { 3 - 5 } & $9.5 \pm 2.7$ & $6.1 \pm 1.6^{\mathrm{b}}$ & $2.8 \pm 1.5$ & $1.2 \pm 0.8$ \\
& & $(66.3 \pm 5.0)$ & $(26.3 \pm 8.5)$ & $(11.8 \pm 7.0)$ \\
\hline
\end{tabular}

Means with different superscripts differ significantly $(P<0.05)$.

$200 \mu \mathrm{l}$ aliquots were assayed without extraction for oestradiol (Bélanger et al., 1990), and $50 \mu \mathrm{l}$ aliquots were assayed for progesterone (Lafrance and Goff, 1985) and testosterone (Price, 1994). The progesterone assay was modified by the use of an iodinated tracer (Amersham Canada, Oakville, Ontario), and separation of free and bound fractions by second antibody precipitation. All samples for each steroid within an experiment were run in single assays. The oestradiol assay had an intra-assay coefficient of variation (CV) of $9.4 \%$ and a sensitivity equivalent to $0.5 \mathrm{ng} \mathrm{ml}^{-1}$. The sensitivity of the progesterone assay was equivalent to $2 \mathrm{ng}$ $\mathrm{ml}^{-1}$, and the intra-assay $\mathrm{CV}$ was $5.4 \%$. The testosterone assay had a detection limit equivalent to $6 \mathrm{ng} \mathrm{ml}^{-1}$, and an intra-assay $\mathrm{CV}$ of $9.1 \%$.

Concentrations of dimeric inhibin were determined in dilutions of 1:1000 and 1:2000 of follicular fluid, by sandwich ELISA as described by Price et al. (1995b). The standard was recombinant human $32 \mathrm{kDa}$ inhibin (generously supplied by Genentech, S. San Francisco, CA). The reaction signal was amplified using a commercially available kit (ELISA Amplification System: Gibco BRL Canada). The sensitivity of the assay was equivalent to $5 \mathrm{ng} \mathrm{ml}^{-1}$ follicular fluid. All samples were run in five plates, with intra- and interassay CVs of 4 and $10 \%$, respectively.

\section{Statistical analysis}

Numbers of oocytes recovered, and embryos cleaving and developing to eight-cell and blastocyst stages, and steroid hormone concentrations did not follow a normal distribution and were therefore log-transformed before analysis. The percentage of cultured embryos reaching defined developmental stages were transformed to arcsines for analysis, but are presented as percentages for clarity. Binomial data were analysed by $\chi^{2}$ test. Data were analysed by ANOVA (with repeated measures for hormone data in Expt 1), and means are presented as least squares means \pm SEM. Comparison of means was performed with the Tukey-Kramer HSD test, and linear correlations between variables were tested with the Pearson correlation coefficient (SAS Institute Inc., Cary, NC).

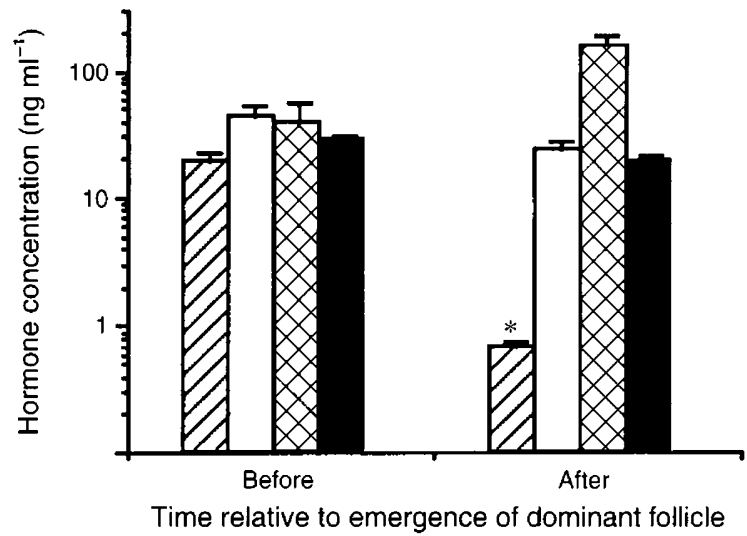

Fig. 1. Mean ( \pm SEM) concentrations of oestradiol ( $\square)$, testosterone $(\square)$, progesterone (ख) and dimeric inhibin $(\boldsymbol{\square})$ in individual small (2-7 mm) bovine follicles collected before (mean of $7.5 \pm 1.1$ follicles assayed per heifer; $n=4$ heifers) or after (mean of $6.2 \pm 0.9$ follicles assayed per heifer; $n=6$ heifers) emergence of the first-wave dominant follicle. *Significantly different from value before emergence of dominant follicle.

\section{Results}

\section{Experiment 1}

The mean numbers of oocytes collected, embryos cleaving and developing to eight-cell and blastocyst stages are shown (Table 1). The mean number of oocytes recovered from Group 1 were approximately double that in Group 2, although the difference did not reach statistical significance $(P=0.08)$. Forty-eight hours after in vitro fertilization, significantly fewer cleavage stage embryos were obtained from oocytes recovered after the emergence of the dominant follicle $(P<0.05)$. The percentage of oocytes that cleaved, and developed to eight-cell and blastocyst stages are also shown (Table 1). No differences were detected between groups. There was a marked tendency for an increased number of nuclei in Group 1 compared with Group 2 blastocysts $(86.9 \pm 9.3$ versus $50.5 \pm 9.7 ; P=0.06)$, and the proportion of cows producing at least one blastocyst was significantly higher before compared with after emergence of the dominant follicle ( 4 of 4 versus 2 of 6 cows; $P<0.05$ ). 
Table 2. Mean ( \pm SEM) numbers of oocytes recovered per cow, and numbers (percentages in parentheses) of embryos that developed to cleavage and eight-cell stage by day 2 of culture, and to blastocyst stage by day 7 of culture, obtained from small antral follicles of cows with ( $n=8$ cows) or without ( $n=7$ cows) of a large dominant follicle

\begin{tabular}{|c|c|c|c|c|}
\hline & \multirow{2}{*}{$\begin{array}{c}\text { Average } \\
\text { number } \\
\text { of oocytes }\end{array}$} & \multicolumn{3}{|c|}{ Number of embryos } \\
\hline & & Cleaved & Eight-cell & Blastocyst \\
\hline Dominant follicle absent & $8.1 \pm 2.1$ & $\begin{array}{c}7.1 \pm 1.5 \\
\langle 93.0 \pm 3.6\rangle\end{array}$ & $\begin{array}{r}5.7 \pm 1.3 \\
(73.8 \pm 7.0)\end{array}$ & $\begin{array}{r}2.9 \pm 0.5 \\
(48.6 \pm 11.3)\end{array}$ \\
\hline Dominant follicle present & $7.6 \pm 1.0$ & $\begin{array}{c}6.4 \pm 2.0 \\
(84.7 \pm 8.7)\end{array}$ & $\begin{array}{c}5.1 \pm 2.1 \\
(55.7 \pm 10.7)\end{array}$ & $\begin{array}{c}3.6 \pm 1.3 \\
(39.4 \pm 6.4)\end{array}$ \\
\hline
\end{tabular}

The mean number of follicles used for hormone assay was $7.5 \pm 1.1$ and $6.2 \pm 0.9$ follicles per cow, in Groups 1 and 2, respectively $(P>0.05)$. Concentrations of oestradiol in the follicular fluid were significantly higher in follicles recovered before compared with after the emergence of the dominant follicle ( $P<0.001$; Fig. 1). There was no effect of group on mean testosterone, progesterone or dimeric inhibin concentrations $(P>0.05$; Fig. 1$)$. Follicular hormone concentrations were not correlated with oocyte developmental competence.

\section{Experiment 2}

The mean number of oocytes collected, and the percentage of these oocytes progressing to cleavage, eight-cell and blastocyst stages are shown (Table 2). There were no significant differences between groups for numbers of oocytes recovered, or for developmental capacity.

Concentrations of oestradiol, testosterone and progesterone in follicular fluid of the dominant follicles, and pooled fluid from small follicles in the presence or absence of a dominant follicle are given (Fig. 2). Oestradiol concentrations were significantly higher in large dominant follicles than in small follicles $(P<0.001)$. Testosterone concentrations in large follicles were lower than those in small follicles in the presence $(P<0.01)$ but not in the absence of a dominant follicle $(P>0.05)$. Progesterone concentrations were not different across follicle groups $(P>0.05)$.

Irrespective of the presence of a dominant follicle, there were significant negative correlations between the concentration of oestradiol in follicular fluid and the percentage of oocytes that formed blastocysts, the percentage of cleaved oocytes that formed eight-cell embryos, and the percentage of cleaved oocytes that formed blastocysts (Fig. 3). Correlations were not observed between oestradiol concentrations and percentage of oocytes that cleaved or reached the eight-cell stage, or between progesterone or testosterone concentrations and developmental capacity.

\section{Discussion}

The study presented here examined the developmental capacity of oocytes from small bovine follicles in relation to endocrine indices of follicle health. Two different approaches were taken, and the results clearly demonstrate that the

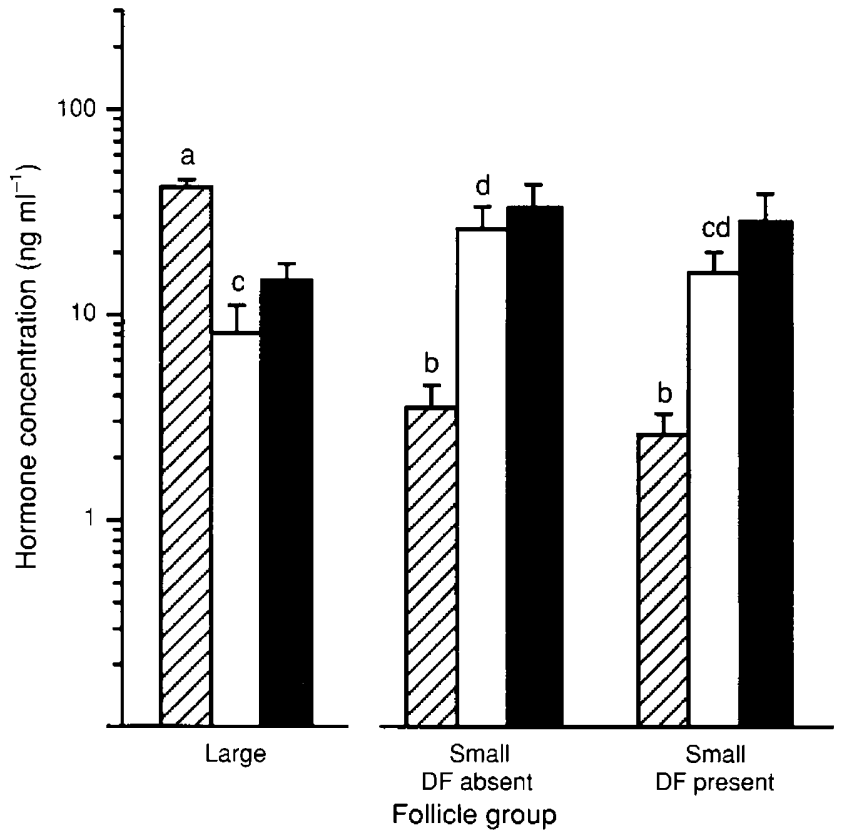

Fig. 2. Mean $( \pm S E M)$ concentrations of oestradiol $(\llbracket)$, testosterone $(\square)$ and progesterone $(\square)$ in large $(>8 \mathrm{~mm})$ follicles, and in pooled follicular fluid from smail $(2-7 \mathrm{~mm})$ follicles collected in the presence ( $n=8$ cows) or absence ( $n=7$ cows) of a large follicle (DF). For each hormone, columns with different superscripts are significantly different $(P<0.05)$ between follicle groups.

developmental competence of oocytes was not significantly affected by the presence or absence of a dominant follicle.

In the first study, small follicles were compared before and after emergence of the large dominant follicle of the first follicular wave. It was expected that after emergence of the dominant follicle, the small subordinate follicles would show signs of atresia. Atresia was observed, as significantly lower concentrations of oestradiol were measured in subordinate small follicles compared with growing small follicles, in agreement with data from large follicles, although at variance with data obtained by Kruip and Dieleman (1985) from follicles of similar size to those studied in the present experiment. Despite the difference in oestradiol and the presence or absence of a dominant follicle, there were no differences in the developmental capacity of the oocytes. 
(a)

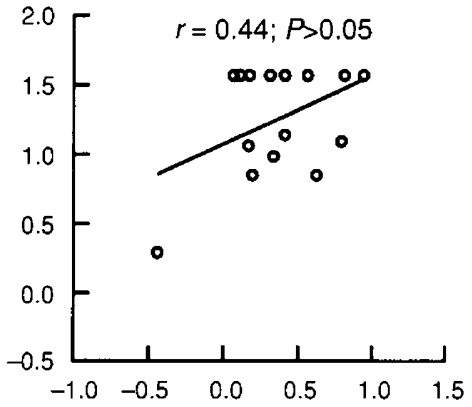

(c)

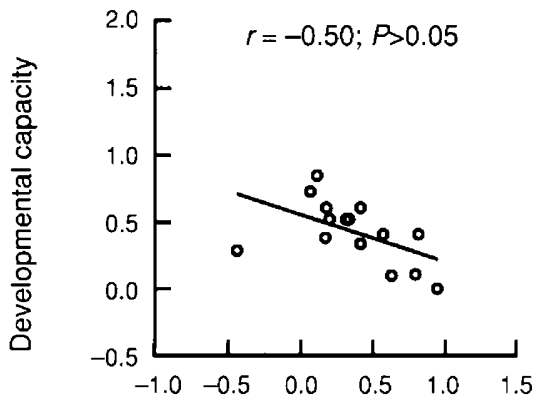

(e)

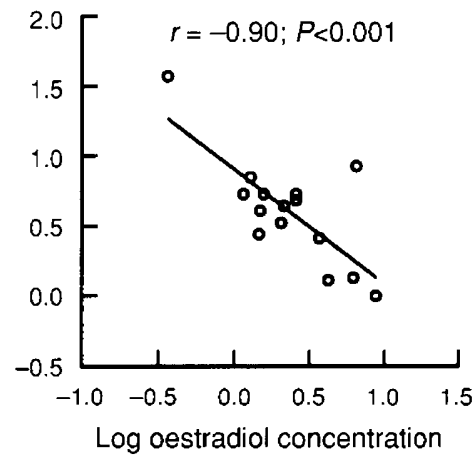

(b)

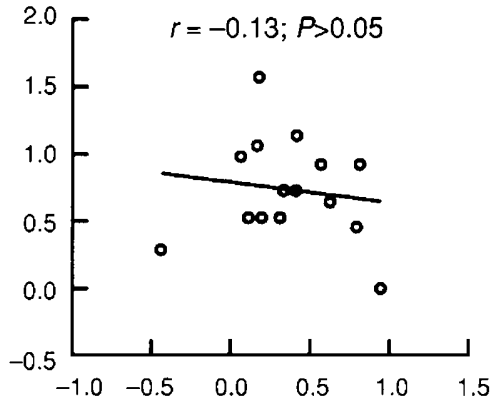

(d)

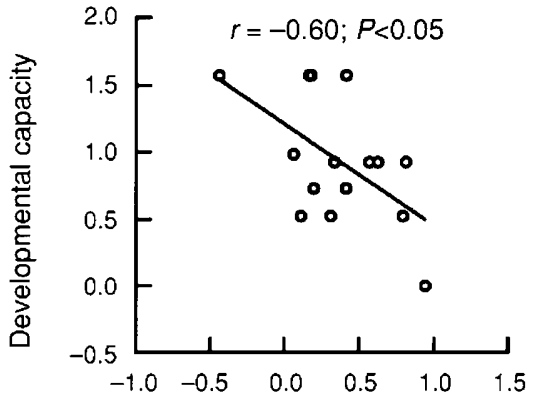

(f)

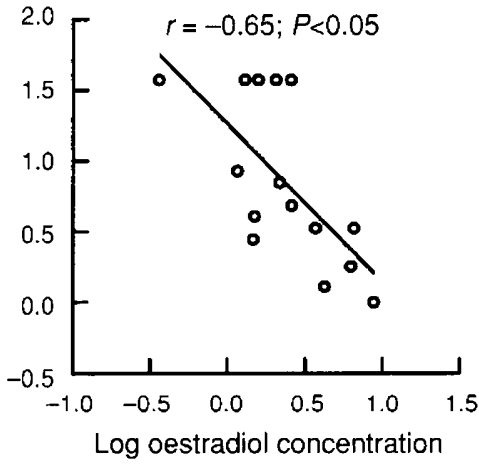

Fig. 3. Linear correlations between oestradiol concentrations in follicular fluid $\left(\log _{10}\right)$ and proportion (arcsine) of bovine oocytes developing to (a) two-cell, (b) eight-cell and (c) blastocyst stages, and proportion of cleaved embryos developing to (d) eight-cell and (e) blastocyst stages, and (f) the proportion of eight-cell embryos developing to blastocysts. Small follicles were collected from pairs of ovaries containing a young corpus luteum, irrespective of the presence of a dominant follicle.

The concentrations of dimeric inhibin presented in this study are markedly lower than those previously reported in bovine follicles. Large, non-atretic follicles were reported to contain $0.5-2.5 \mu \mathrm{g} \mathrm{ml}^{-1}$ (Guilbault et al., 1993) or $1-4 \mu \mathrm{g} \mathrm{ml}^{-1}$ (Price et al., 1995a), based on purified bovine $32 \mathrm{kDa}$ dimeric inhibin standards. The present assay used recombinant human $32 \mathrm{kDa}$ dimeric inhibin as standard, which is approximately 100 times more potent in the assay (Price et al., 1995a). On the basis of these figures, the present values of $20-30 \mathrm{ng}$ recombinant human inhibin $\mathrm{ml}^{-1}$ would be equivalent to $2-3 \mu \mathrm{g}$ purified bovine inhibin $\mathrm{ml}^{-1}$, which is in agreement with previous reports. The present data also indicate that inhibin concentrations in the fluid of small subordinate follicles were not affected by the presence of a dominant follicle, and were therefore not measured in Expt 2.

The total number of cumulus-oocyte complexes obtained before emergence of the dominant follicle was higher than after emergence, as predicted by the growth pattern of the first follicle wave (Savio et al., 1988; Sirois and Fortune, 1988). Owing in part to the large variation within and between 
animals, only the number of cleaved embryos was significantly different between groups. The difference in the number of oocytes obtained may also explain why the proportion of cows producing at least one blastocyst was significantly higher before compared with after emergence of the dominant follicle; if only $11 \%$ of recovered oocytes develop to blastocyst stage, there is a high probability that animals with less than 10 oocytes (as was the case after emergence) would not produce blastocysts. These overall data are at variance with those of Stringfellow et al. (1993), who obtained a greater number of oocytes from days 5-13 of the oestrous cycle compared with days $\mathbf{0}-3$. This latter study may have included a cohort of growing small follicles from the emergence of the second follicle wave in the days 5-13 collection group, and may also have collected oocytes before the emergence of the first wave in the days 0-3 group, thus making the results of the two studies difficult to compare.

One limitation of Expt 1 was the use of different follicles for hormone analysis and for oocyte culture. We attempted to overcome this problem in Expt 2 by pooling follicular contents, removing the oocytes and then recovering the fluid for hormone assay. In this experiment, ovaries from the abattoir were classed as having dominant or nondominant follicles based on the presence of a large $(>8 \mathrm{~mm})$ follicle that was oestrogen-active. However, there were no significant differences in oestradiol concentrations in the fluid of the small follicles, nor in the total numbers of oocytes recovered. This is not easily explained, as ovaries were collected only if they contained a young (Stage 1; Ireland et al., 1980) corpus luteum, and should therefore have been comparable with the early luteal phase follicles in Expt 1. Nevertheless, the data clearly show that oocytes from these follicles were not compromised by the presence of a dominant follicle in the ovaries; this finding is consistent with the results from Expt 1 .

An interesting observation in Expt 2 was the significant negative correlation between follicular oestradiol concentration and the percentage of cleaved oocytes that developed to eight-cell and blastocyst stages. This also is difficult to explain, as the data infer that developmental competence increases as follicles become less oestrogenic (that is, more atretic). These data should be viewed with caution, as hormone assays were performed on fluid pools rather than on individual follicles.

Moor and Trounson (1977) found that a greater number of oocytes from small atretic sheep follicles reached metaphase II compared with non-atretic follicles after maturation in vivo, although, as in the present study, no overall differences in the rate of blastocyst development were detected. It is possible that the oocytes are under inhibition by a follicular secretion, and that as follicles become atretic the secretion of the inhibitory factor decreases. Alternatively, organelle rearrangement that occurs in the oocyte during early follicular atresia in small follicles may mimic those occurring in the preovulatory follicle around the time of the LH surge, as suggested by the electron microscopy study of Assey et al. (1994). This rearrangement may confer some developmental advantage during early atresia.

Cleavage and blastocyst development rates in Expt 2 were approximately three times higher than in Expt I. This may have been caused by an increase in the number of bovine oviductal epithelial cells included in the oocyte culture medium, or by the fact that different personnel performed the fertilization/maturation procedures in Expt 2 compared with Expt 1. There may also have been a seasonal effect, as the higher developmental rates were obtained during the winter months; a similar seasonal effect has been observed in this laboratory during other studies (L. C. Smith, unpublished). The difference in developmental rates was large and clearly warrants further investigation.

In summary, the present study shows that the developmental capacity of oocytes from small follicles is not compromised by the endocrine milieu of the follicle, nor by the presence of a dominant follicle. These findings suggest that the ovarian status of regularly cyclic animals need not be a concern in the collection of oocytes for the bovine embryo transfer industry.

The authors thank N. Houle and his staff for care of the animals, A. Bélanger and A. K. Goff for radioimmunoassay reagents, J. Mather for recombinant inhibin, F. J. Escobar Medina for assistance with ultrasonography, and A. E. Stock for helpful comments on the manuscript. This work was supported by NSERC of Canada (C. A. Price and L. C. Smith), and by the MRC and Cancer Research Campaign (N. P. Groome).

\section{References}

Assey RJ, Hyttel P, Greve T and Purwantara B (1994) Oocyte morphology in dominant and subordinate follicles Molecular Reproduction and Development $37335-344$

Bélanger A, Couture J, Caron S and Roy R (1990) Determination of nonconjugated and conjugated steroid levels in plasma and prostate after separation on C-18 columns Annals of the New York Academy of Sciences 595 $251-259$

Brackett BG and Zuelke KA (1993) Analysis of factors involved in the in vitro production of bovine embryos Theriogenology 39 43-64

Bungartz L and Niemann H (1994) Assessment of the presence of a dominant follicle and selection of dairy cows suitable for superovulation by a single ultrasound examination Journal of Reproduction and Fertility 101 583-591

Callesen $\mathbf{H}$, Greve $\mathrm{T}$ and Hyttel $\mathrm{P}$ (1986) Preovulatory endocrinology and oocyte maturation in superovulated cattle Theriogenology 25 71-86

De Loos F, Van Vliet C, Van Mauric P and Kruip TAM (1989) Morphology of immature bovine oocytes Gamete Research 24 189-204

Grimes RW, Matton P and kreland Jj (1987) A comparison of histological and non-histological indices of atresia and follicular function Biology of Reproduction $3782-88$

Guilbault LA, Grasso F, Lussier JG, Rouillier P and Matton P (1991) Decreased superovulatory responses in heifers superovulated in the presence of a dominant follicle journal of Reproduction and Fertility 91 81-89

Guilbault LA, Rouillier P, Matton P, Glencross RG, Beard AJ and Knight PG (1993) Relationships between the level of atresia and inhibin contents ( $\alpha$ subunit and $\alpha-\beta$ dimer) in morphologically dominant follicles during their growing and regressing phases of development in cattle Biology of Reproduction 48 268-276

Hopko Ireland JL, Good TEM, Knight PG and lreland JJ (1994) Alterations in amounts of different forms of inhibin during follicular atresia Biology of Reproduction 50 1265-1276

Ireland JJ and Roche JF (1983) Development of nonovulatory antral follicles in heifers: changes in steroids in follicular fluid and receptors for gonadotropins Endocrinology 112 150-156

Ireland JJ, Murphree RL and Coulson PB (1980) Accuracy of predicting stages of bovine estrous cycle by gross appearance of the corpus luteum Journal of Dairy Science 63 155-160

Kruip TAM and Dieleman SJ (1982) Macroscopic classification of bovine follicles and its validation by micromorphological and steroid biochemical procedures Reproduction. Nutrition, Development 22 465-473 
Kruip TAM and Dieleman SJ (1985) Steroid hormone concentrations in the fluid of bovine follicles relative to size, quality and stage of the oestrous cycle Theriogenology 24 395-408

Lafrance $M$ and Goff AK (1985) Effect of pregnancy on oxytocin-induced release of prostaglandin $\mathrm{F}_{2 \mathrm{v}}$ in heifers Biology of Reproduction 33 1113-1119

Moor RM and Trounson AO (1977) Hormonal and follicular factors affecting maturation of sheep oocytes in vitro and their subsequent developmental capacity Journal of Reproduction and Fertility 49 101-109

Parrish JJ, Susko-Parrish JL, Leibfriedge-Ruthedge ML, Critser ES, Eyestone WH and First NL (1986) Bovine in-vitro fertilization with frozen-thawed semen Theriogenology 25 591-600

Price CA (1994) Evidence that testosterone and inhibin do not interact in the control of FSH in rams Theriogenology 41 471-482

Price CA, Carrière PD, Bhatia B and Groome NP (1995a) Comparison of hormonal and histological changes during follicular growth, as measured by ultrasonography, in cattle Journal of Reproduction and Fertility 103 63-68

Price CA, Salah N and Groome NP (1995b) Plasma concentrations of dimeric inhibin and oestradiol in heifers undergoing superovulation with eCG or FSH Journal of Reproduction and Fertility Supplement 49 507-510

Pursel VG, Wall RG, Rexroad CE, Hammer RE and Brinster RL (1985) A rapid whole-mount staining procedure for nuclei of mammalian embryos Theriogenology 24 687-691
Savio JD, Keenan L, Boland MP and Roche JF (1988) Pattern of growth of dominant follicles during the oestrous cycle of heifers Journal of Reproduction and Fertility 83 663-671

Sirois J and Fortune JE (1988) Ovarian follicular dynamics during the estrous cycle in heifers monitored by real-time ultrasonography Biology of Reproduction 39 308-317

Spicer LJ and Zinn SA (1987) Relationship between concentrations of cortisol in ovarian follicular fluid and various biochemical markers of follicular differentiation in cyclic and anovulatory cattle Journal of Reproduction and Fertility $81221-226$

Spicer LJ, Matton P, Echternkamp SE, Convey EM and Tucker HA (1987) Relationships between histological signs of atresia, steroids in follicular fluid, and gonadotropin binding in individual bovine antral follicles during postpartum anovulation Biology of Reproduction 36 890-898

Stringfellow DA, Riddell MG, Riddell KP, Carson RL, Smith RC, Gray BW and Wright JC (1993) Use of in vitro fertilization for production of calves from involuntary cull cows Journal of Assisted Reproduction and Genetics 10 $280-285$

Xu KP, Yadav BR, Rorie RW, Plante L, Betteridge KJ and King WA (1992) Development and viability of bovine embryos derived from oocytes matured and fertilized in vitro and co-cultured with bovine oviducal epithelial cells Journal of Reproduction and Fertility 94 33-43 